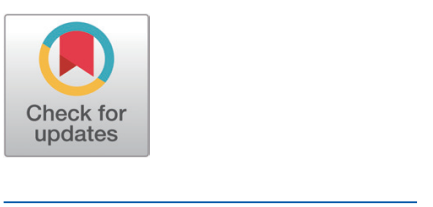

Received: Nov 10, 2020

Revised: Dec 29, 2020

Accepted: Feb 27, 2021

*Corresponding author Hang Lee

College of Veterinary Medicine, Seoul National University, Seoul 08826

Korea.

Tel: +82-2-880-1274

E-mail: hanglee@snu.ac.kr

Byung Sun Kim

Department of Equine Science, Cheju Halla University, Jeju 63092, Korea.

Tel: +82-64-741-7663

E-mail: bskim0929@chu.ac.kr

Copyright $\odot 2021$ Korean Society of

Animal Sciences and Technology.

This is an Open Access article distributed under the terms of the

Creative Commons Attribution

Non-Commercial License (http:// creativecommons.org/licenses/by$\mathrm{nc} / 4.0 /$ ) which permits unrestricted non-commercial use, distribution, and reproduction in any medium, provided the original work is properly cited.

ORCID

Kyung Eun Lee

https://orcid.org/0000-0002-6938-6621 Joon Gyu Kim

https://orcid.org/0000-0002-6246-2097 Hang Lee

https://orcid.org/0000-0003-0264-6289

Byung Sun Kim

https://orcid.org/0000-0003-1008-2305

Competing interests

No potential conflict of interest relevant to this article was reported.

Funding sources

This study was partially supported by the Research Institute for Veterinary

\section{Behavioral and cardiac responses in mature horses exposed to a novel object}

\author{
Kyung Eun Lee ${ }^{1}$, Joon Gyu Kim², Hang Lee ${ }^{1 *}$ and Byung Sun Kim ${ }^{2 *}$ \\ ${ }^{1}$ Center for Animal Welfare Research, College of Veterinary Medicine, Seoul National University, Seoul \\ 08826, Korea \\ ${ }^{2}$ Department of Equine Science, Cheju Halla University, Jeju 63092, Korea
}

\section{Abstract}

This study aimed to investigate whether breed, sex, and age affected temperament differently (more or less neophobic) in mature horses during a novel object test. The study included Jeju crossbred $(n=12$, age $=9.42 \pm 4.57 y)$, Thoroughbred $(n=15$, age $=10.73 \pm 3.09 y)$, and Warmblood horses $(n=12$, age $=13.08 \pm 3.55 y)$ with the females $(n=22$, age $=11.36 \pm 4.24$ $y$ ) and geldings $(n=17$, age $=10.65 \pm 3.66 y)$. Jeju crossbreds (Jeju horse $\times$ Thoroughbred) are valuable considering their popular usage in Korea, but limited studies have explored temperament of Jeju crossbred horses. A trained experimenter touched the left side of the neck with a white plastic bag (novel object). The test ended when the horse stopped escape response and heart rate (HR) dropped to baseline. Behavioral score and escape duration were measured as behavioral variables. Multiple variables related to $\mathrm{HR}$ and heart rate variability (HRV) were measured to reflect emotional state. These included basal HR (BHR), maximum $\mathrm{HR}$ (MHR), delay to reach maximum heart rate (Time to MHR), standard deviation of beatto-beat intervals (SDNN), root mean square of successive differences (RMSSD), and ratio of low to high frequency components of a continuous series of heartbeats (LF/HF). Statistics revealed that Thoroughbreds had significantly higher behavioral scores, and lower RMSSD than Jeju crossbreds $(p<0.05)$, suggesting greater excitement and fear to the novel object in Thoroughbreds. None of the behavioral or cardiac parameters exhibited sex differences $(p<$ $0.05)$. Age was negatively correlated with SDNN and RMSSD $(p<0.05)$, indicating that older horses felt more anxiety to the novelty than younger horses. Thoroughbreds and females had distinct correlations between behavioral and HRV variables in comparison with other groups $(p<0.05)$, implying that escape duration might be a good indicator of stress, especially in these two groups. These results are expected to improve equine welfare, safety and utility, by providing insights into the temperament of particular horse groups, to better match reactivity levels with specific functions.

Keywords: Equine, Temperament, Novelty, Behavior, Heart rate, Heart rate variability

\section{INTRODUCTION}

As prey animals, horses have evolved a strong susceptibility to fear-eliciting stimuli, increasing survival 
Science, Seoul National University.

Acknowledgements

We are grateful to Myung Sun Chun and Janne Winther Christensen for the valuable comments and advices to this manuscript. We also thank Gemma Pearson for support which was critical for HRV data correction.

Availability of data and material Upon reasonable request, the datasets of this study can be available from the corresponding author.

Authors' contributions

Conceptualization: Kim BS

Data curation: Lee KE, Kim JG, Kim BS

Formal analysis: Lee KE.

Funding acquisition: Lee $\mathrm{H}$

Investigation: Lee KE, Kim JG, Kim BS.

Methodology: Kim JG, Kim BS.

Project administration: Lee $\mathrm{H}$.

Resources: Kim BS, Kim JG.

Software: Lee KE, Kim JG.

Supervision: Kim BS.

Visualization: Lee KE, Lee $\mathrm{H}$.

Writing - original draft: Lee KE.

Writing - review \& editing: Kim JG, Lee H, Kim BS.

Ethics approval and consent to participate All procedures were approved by the Institutional Animal Care and Use Committee at Seoul National University (license: SNU190121-3-1). among individuals that react quickly to any hint of potential danger [1]. This characteristic contributes to determining horse temperament and is heritable. Thus, domestic horses share this neophobic response with their wild ancestors. Temperament has a strong genetic component in horses [2], and this explains why, even after habituation, innately fearful horses will still exhibit flight responses to novel objects [3]. Given that horse characteristics are very important to riders and breeders for improving safety and horse welfare [4], there is considerable interest in understanding equine temperament.

In multiple animal species, behavioral, heart rate (HR), and heart rate variability (HRV) responses are the most commonly used variables in predicting temperament traits [5]. Many studies have evaluated the temperament and emotional state of horses through observing behavioral and cardiac changes after novel object tests [6-8]. The consensus from novel object experiments is that behavioral and cardiac activity are significantly correlated and they are complementary measures of temperament each other, which should improve reliability. However, limited studies have investigated behavioral and cardiac parameters from a temporal perspective in temperament tests. Thus, temporal variables were included in this study (escape duration for behavior, and time to maximum heart rate [MHR] for HR), to explore both the degree of the surprise response to the novel object, and the duration of that response. These parameters may help further elucidate the temperament traits of horses. The current study investigated breed, sex, and age differences in temperament using behavioral, HR and HRV responses to an unfamiliar, complex, stimulating object in mature horses.

In Jeju (a native Korean pony) crossbred horse (Jeju horse $\times$ Thoroughbred), which is one of the subject horse breeds, several reports explored the genetic basis of temperament, with the estimation of genetic parameters, and genetic correlations between temperament traits $[9,10]$. However, relationships between behavior, physiological responses, and temperament, have not been studied in this breed. These horses are especially common in youth horseback riding in Korea [11], because they are similar in size to ponies. It is widely known among people that Jeju crossbred horses are bolder and less prone to startle, compared with other breeds in the same environment, and their advantages include strong hooves, a high feed efficiency, and endurance [12]. Horseback riding is an increasingly popular recreational activity in Korea, and given this economic significance, further studies on Jeju crossbreds are warranted.

This study aimed to explore breed, sex, and age differences in the temperament using a novel object test in mature horses, ages of which were in range of being ridden as horseback riding. Our subjects included Jeju crossbreds, Thoroughbreds, and Warmbloods, the three most popular breeds for horseback riding in Korea. We hypothesized that breed, sex, and age would differentially affect horse temperament. Our results will benefit the selection of horses with a temperament appropriate for a specific purpose, thus increasing their utility and welfare. Horses with an optimal temperament will also improve human safety when horseback riding, potentially increasing the activity's popularity and economic benefits.

\section{MATERIALS AND METHODS}

\section{Animals and management}

The study included 12 Jeju crossbred horses (eight mares and four geldings), 15 Thoroughbred horses (eight mares and seven geldings), and 12 Warmblood horses (six mares and six geldings). Jeju crossbreds ages were $9.42 \pm 4.57$ years; Thoroughbreds $10.73 \pm 3.09$ years; and Warmbloods $13.08 \pm 3.55$ years. Age distributions did not significantly differ within both breed and sex groups $(p$ $>0.05$ ). Horses were part of the horseback riding classes at the Cheju Halla University (Jeju island, 
Korea), and were not ridden more than once a day. On non-riding days, they were exercised for an hour on a horse-walker. All subjects were housed under comparable conditions in individual box stalls. Water was provided ad libitum in automatic drinkers, while feed (hay and concentrates) were provided three times a day. All animals were checked to ensure that they were in good condition, and had no obvious cardiac abnormalities that could affect HRV. All the horses in the University facility were subject to the same management principles regardless of the breed, sex or age.

\section{Experimental design}

\section{Test environment}

The experiments took place in a $30 \mathrm{~m} \times 70 \mathrm{~m}$ indoor riding arena, located in a building adjacent to the stables. All horses had been exercised in the site at least 5 days a week for over a year.

\section{Test objects}

The stimulus in the novel object test was a white plastic bag $(25 \times 30 \mathrm{~cm})$. The plastic bag was tied to the end of a slender, flexible stick about $1 \mathrm{~m}$ long. Plastic bags are a complex stimulus combining visual, auditory, and tactile elements, making them a common choice for such studies [13-15].

\section{Test procedures}

The test was conducted between 09:00 am and 11:00 am. A halter and with a $5 \mathrm{~m}$ lead rope was used to lead the horses. A handler already well known to the subjects, who was skilled in training horses and very experienced with this test, did not change during the whole experiments. The horse was affixed with HR equipment upon entry to the arena, and was left for 10 min to adapt to the situation. During this period, the experimenter stood quietly next to the horse with hiding the stimuli behind his back, but without touching the subject. An assistant familiar with the horses then measured baseline HR. Subsequently, the experimenter gently exposed the stimuli and touched the area between the horse's left shoulder and neck at intervals of about one second. If the horse exhibited flight responses, the tester loosened the lead rope but held onto the end. The test ended when evasion responses ceased and HR back at baseline. Throughout the experiment, the second experimenter checked HR, and informed the first experimenter when he should stop the touching action.

\section{Behavioral observations}

Two variables for behavior were used; behavioral score and escape duration (Table 1). Behavioral score was assessed using the following scale by an assistant: 1 (very fearless, no reaction) to 5 (very fearful, showing flight response) (Table 2). Behavioral scoring system was adapted from previous studies $[16,17]$. An assistant recorded videos of the novel object test at approximately $4 \mathrm{~m}$ from the subject horse. Videos were later assessed for behavioral score and scored to calculate escape duration, beginning from stimulus initiation to the cessation of responses.

\section{Monitoring and videotaping of heart rate and heart rate variability}

HR was recorded continuously from 2 min before stimulus introduction to the end of the experiment, using a Polar V800 Equine heart rate sensor (Polar Electro OY, Kempele, Finland). Normally 5 min intervals are recommended for HRV analysis, but previous findings identified that there were no significant differences in some HRV features between $5 \mathrm{~min}$ and $2 \mathrm{~min}$ intervals when detecting mental stress [18]. All horses were familiar with the sensor because it is used for periodic health examinations. The device consisted of an electrode belt with a built-in transmitter and a wristwatch receiver. Water and conductive gel were used to improve electrode-to-skin contact. 
Table 1. Ethogram of behaviors recorded in the novel object test

\begin{tabular}{ll}
\hline Behavioral parameter & \multicolumn{1}{c}{ Definition } \\
\hline Behavioral score & $\begin{array}{l}\text { Rated behavioral reactivity by the experimenter during the test according to the } \\
\text { behavioral reactivity scale Table 2. }\end{array}$ \\
Escape duration (s) & $\begin{array}{l}\text { The time from stimulus initiation to the end of escaping responses. The end point } \\
\text { was decided as the point in time when the test horse first stood still, and did not } \\
\text { exhibit physical signs of fearfulness over 15 s (e.g., stiff neck muscles and head } \\
\text { moving along with the stimulus). }\end{array}$ \\
\hline
\end{tabular}

Table 2. Behavioral score during the novel object test

\begin{tabular}{cl}
\hline Behavioral score & \multicolumn{1}{c}{ Description } \\
\hline 5 & $\begin{array}{l}\text { Horse suddenly jumps away more than } 2 \text { meters from the novel object, typically followed } \\
\text { by trotting, galloping, alertness, and possibly snorting; keeps far away from the novel. } \\
\text { object despite handler encouragement. }\end{array}$ \\
& $\begin{array}{l}\text { Horse is alert and suddenly jumps away less than } 2 \text { meters from the novel object, typi- } \\
\text { cally followed by trotting, galloping, further alertness, and possibly snorting. }\end{array}$ \\
& $\begin{array}{l}\text { Horse escapes and exhibits vigilant behavior (elevated neck, head, and ears oriented } \\
\text { toward the test stimulus), typically followed by trotting, galloping, alertness, and possibly } \\
\text { snorting. }\end{array}$ \\
& Horse escapes but is easily restrained. \\
1 & Horse does not react to the novel object and approaches it without hesitation. \\
\hline
\end{tabular}

Data were uploaded to Polar Flow software for storage, and analyzed using Kubios HRV software (Kubios standard 3.2.0, Biomedical Signal Analysis Group, Department of Applied Physics, University of Kuopio, Kuopio, Finland). Measurements of HR and HRV occurred after visual inspection to correct any artifacts by setting the custom filter to 0.3 , according to the previous study [19].

Six HR and HRV parameters were determined per horse (Table 3). Basal HR (BHR) $5 \mathrm{~s}$ before the introduction of the plastic bag, and maximum HR (MHR) during the test were measured. Delay to reach MHR (Time to MHR) from the beginning of the test was measured in seconds. Standard deviation of the beat-to-beat intervals (SDNN), the root mean square of the successive differences (in milliseconds) (RMSSD), and the low frequency/high frequency ratio (LF/HF) were analyzed as HRV parameters (Table 3). SDNN measures the state of balance between sympathetic and parasympathetic activities of the heart. RMSSD is normally used to estimate high frequency beat-to-beat variations that represent vagal regulatory activity [5]. Lower SDNN and RMSSD values indicate a shift towards sympathetic dominance, while higher values of these parameters reflect a shift towards parasympathetic dominance. The $\mathrm{LF} / \mathrm{HF}$ ratio indicates sympathetic activity under physical or psychological stressors. An increase in LF/HF means a regulatory shift toward sympathetic dominance [8].

Table 3. Cardiac parameters in response to the novel object

\begin{tabular}{ll}
\hline Cardiac parameters (unit) & \multicolumn{1}{c}{ Definition } \\
\hline BHR (bpm) & Basal heart rate measured before $5 \mathrm{~s}$ of plastic-bag introduction. \\
MHR (bpm) & Maximum heart rate during the novel object test. \\
Time to MHR (s) & Delay to reach maximum heart rate from the beginning of the test. \\
SDNN (ms) & Standard deviation of the beat-to-beat intervals. \\
RMSSD (ms) & Square root of the mean squared differences of successive beat-to-beat intervals. \\
LF/HF & Ratio of low frequency (LF) to high frequency (HF) components of a continuous \\
& series of beats (power spectrum). \\
\hline
\end{tabular}

bpm, beats per minute; ms, milli seconds. 


\section{Statistical analysis}

Data normality was determined with quantile-quantile (QQ)-plots and the Shapiro-Wilk's test. Non-normal data (escape duration, Time to MHR, SDNN, RMSSD, and LF/HF) were logtransformed. Significance was set at $p<0.05$.

Between-breed differences in behavior and HR parameters were analyzed with a one-way analysis of variance (ANOVA), followed by a post-hoc Tukey's honest significant difference (HSD) test. Independent sample $t$-tests were conducted to look for sex differences in response variables. A breed $\times$ sex interaction was tested using a two-way ANOVA and Tukey's HSD test. Age effects were analyzed with Pearson correlations. Pearson correlation coefficients between behavioral and cardiac parameters were calculated within breed and sex.

\section{RESULTS}

Two-way ANOVA revealed that the breed $\times$ sex interaction was not significant in each dependent parameter $(p>0.05)$

\section{Breed}

Breed significantly affected behavioral score, but not escape duration (Table 4). Thoroughbreds had the highest behavioral scores $(3.73 \pm 0.93)$, followed by Warmblood $(3.58 \pm 0.95)$ and Jeju crossbred horses $(2.75 \pm 1.01)$. Importantly, Thoroughbreds showed a significantly higher reactivity than Jeju crossbreds $\left(F_{2,36}=3.556, p=0.039\right)$. However, Warmbloods were intermediate in their responses, and did not show striking differences compared with the others. Escape duration did not differ among breeds $(p>0.05)$. Jeju crossbreds had a significantly higher BHR and RMSSD (BHR: $44.42 \pm 5.79$; RMSSD: $68.50 \pm 21.18$ ) than Thoroughbreds (BHR: $40.27 \pm 4.19$; RMSSD: $49.12 \pm$ 16.81) $(p<0.05)$, with Thoroughbreds and Warmblood horses similar in both parameters (Table 4). Furthermore, MHR, Time to MHR, SDNN, and LF/HF did not vary among breeds $(p>0.05)$.

\section{Sex \& Age}

Females and geldings did not differ significantly in behavioral or cardiac parameters (Table $4, p$ > 0.05).

Age was not correlated with any behavioral reactions (Table 5, $p>0.05$ ). Age did not affect any $\mathrm{HR}$ variables or $\mathrm{LF} / \mathrm{HF}$, but SDNN and RMSSD decreased significantly with increasing horse age (SDNN: $r=-0.488, p=0.002$; RMSSD: $r=-0.416, p=0.008$ ).

Table 4. Means \pm SD of behavioral and cardiac parameters, calculated for breed and sex

\begin{tabular}{|c|c|c|c|c|c|c|c|c|c|}
\hline & \multirow[b]{2}{*}{$\mathbf{N}$} & \multicolumn{2}{|c|}{ Behavior } & \multicolumn{3}{|c|}{ Heart rate } & \multicolumn{3}{|c|}{ Heart rate variability } \\
\hline & & $\begin{array}{l}\text { Behavioral } \\
\text { score }\end{array}$ & $\begin{array}{c}\text { Escape } \\
\text { duration (s) }\end{array}$ & $\begin{array}{c}\text { BHR } \\
(\mathrm{bpm})\end{array}$ & $\begin{array}{c}\text { MHR } \\
(\mathrm{bpm})\end{array}$ & $\begin{array}{l}\text { Time to } \\
\text { MHR (s) }\end{array}$ & $\begin{array}{l}\text { SDNN } \\
(\mathrm{ms})\end{array}$ & $\begin{array}{c}\text { RMSSD } \\
\text { (ms) }\end{array}$ & LF/HF \\
\hline \multicolumn{10}{|l|}{ Breed } \\
\hline Jeju crossbred & 12 & $2.75 \pm 1.01^{\mathrm{a}}$ & $98.58 \pm 48.23^{\mathrm{a}}$ & $44.42 \pm 5.79^{a}$ & $132.42 \pm 13.31^{\mathrm{a}}$ & $37.00 \pm 12.96^{\mathrm{a}}$ & $86.98 \pm 33.11^{\mathrm{a}}$ & $68.50 \pm 21.18^{\mathrm{a}}$ & $1.76 \pm 0.79^{\mathrm{a}}$ \\
\hline Thoroughbred & 15 & $3.73 \pm 0.93^{b}$ & $118.27 \pm 75.36^{a}$ & $40.27 \pm 4.19^{\mathrm{ab}}$ & $146.07 \pm 23.74^{\mathrm{a}}$ & $40.87 \pm 19.81^{a}$ & $66.79 \pm 21.72^{\mathrm{a}}$ & $49.12 \pm 16.81^{b}$ & $4.24 \pm 3.94^{\mathrm{a}}$ \\
\hline Warmblood & 12 & $3.58 \pm 0.95^{\mathrm{ab}}$ & $118.33 \pm 52.82^{\mathrm{a}}$ & $39.42 \pm 4.86^{\mathrm{b}}$ & $137.58 \pm 15.54^{\mathrm{a}}$ & $57.67 \pm 31.92^{\mathrm{a}}$ & $66.78 \pm 19.35^{a}$ & $50.48 \pm 13.45^{\mathrm{ab}}$ & $3.88 \pm 3.62^{a}$ \\
\hline \multicolumn{10}{|l|}{ Sex } \\
\hline Female & 22 & $3.45 \pm 1.08^{\mathrm{a}}$ & $109.05 \pm 62.49^{\mathrm{a}}$ & $41.95 \pm 5.24^{\mathrm{a}}$ & $141.50 \pm 16.62^{\mathrm{a}}$ & $41.82 \pm 18.24^{\mathrm{a}}$ & $69.28 \pm 29.66^{\mathrm{a}}$ & $52.60 \pm 20.51^{a}$ & $3.72 \pm 3.91^{\mathrm{a}}$ \\
\hline Gelding & 17 & $3.29 \pm 1.02^{\mathrm{a}}$ & $116.35 \pm 61.07^{a}$ & $40.41 \pm 5.41^{a}$ & $136.35 \pm 22.28^{a}$ & $48.76 \pm 29.99^{a}$ & $77.81 \pm 21.78^{\mathrm{a}}$ & $59.25 \pm 17.24^{a}$ & $2.90 \pm 2.42^{\mathrm{a}}$ \\
\hline
\end{tabular}

Different letters within breed or sex group in a single column indicate significance at $p<0.05$.

BHR, basal heart rate; bpm, beats per minute; MHR, maximum heart rate; SDNN, standard deviation of the beat-to-beat intervals; ms, milli seconds; RMSSD, root mean square of successive differences; LF/HF, the ratio of low frequency to high frequency components of continuous series of beats (power spectrum). 
Table 5. Correlations in parameters studied in the novel object test with regard to the age of horse

\begin{tabular}{|c|c|c|c|c|c|c|c|c|}
\hline & \multicolumn{2}{|c|}{ Behavior } & \multicolumn{3}{|c|}{ Heart rate } & \multicolumn{3}{|c|}{ Heart rate variability } \\
\hline & $\begin{array}{l}\text { Behavioral } \\
\text { score }\end{array}$ & $\begin{array}{c}\text { Escape } \\
\text { duration (s) }\end{array}$ & $\begin{array}{c}\text { BHR } \\
(\mathrm{bpm})\end{array}$ & $\begin{array}{c}\text { MHR } \\
\text { (bpm) }\end{array}$ & $\begin{array}{l}\text { Time to } \\
\text { MHR (s) }\end{array}$ & $\begin{array}{l}\text { SDNN } \\
(\mathrm{ms})\end{array}$ & $\begin{array}{c}\text { RMSSD } \\
(\mathrm{ms})\end{array}$ & LF/HF \\
\hline Age & 0.165 & 0.118 & 0.225 & 0.187 & 0.267 & $-0.488^{*}$ & $-0.416^{*}$ & 0.073 \\
\hline
\end{tabular}

${ }^{*} p<0.05$.

$\mathrm{BHR}$, basal heart rate; bpm, beats per minute; MHR, maximum heart rate; SDNN, standard deviation of the beat-to-beat intervals; ms, milli seconds; RMSSD, root mean square of successive differences; LF/HF, the ratio of low frequency to high frequency components of continuous series of beats (power spectrum).

Table 6. Correlations between behavioral and cardiac parameters in the novel object test, grouped by breed and sex

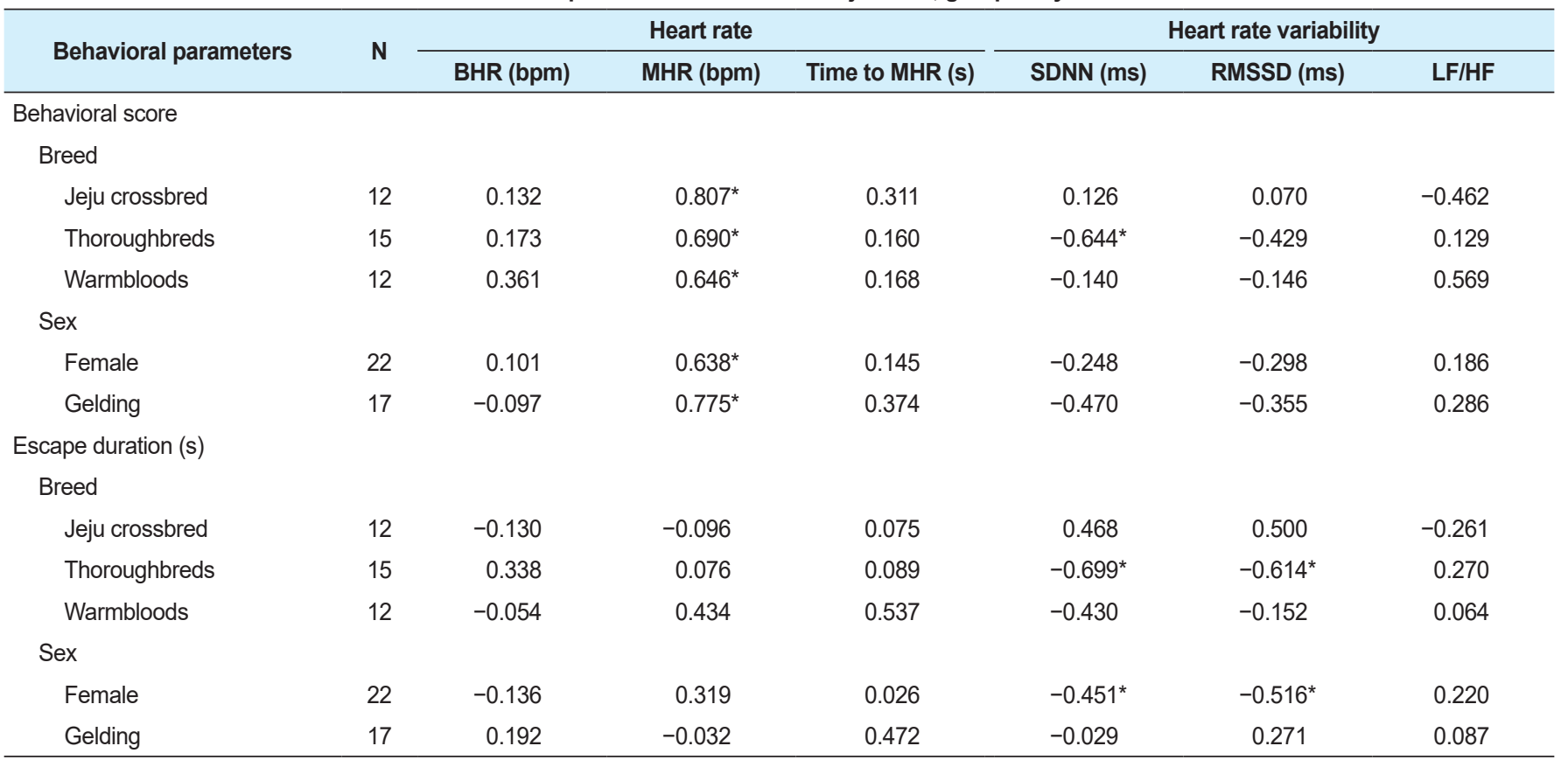

${ }^{*} p<0.05$.

$\mathrm{N}$, the total number of horses used for a particular group; BHR, basal heart rate; bpm, beats per minute; MHR, maximum heart rate; SDNN, standard deviation of the beat-to-beat intervals; ms, milli seconds; RMSSD, root mean square of successive differences; LF/HF, the ratio of low frequency to high frequency components of continuous series of beats (power spectrum).

Correlations between behavioral and cardiac parameters in the novel object test

Behavioral score was correlated with MHR in all breeds (Table 6), with the highest positive correlation in Jeju crossbreds $(r=0.807, p=0.002)$. However, other significant correlations between behavioral and cardiac indices were only detected in Thoroughbreds, and not in the others. Specifically, among Thoroughbreds, behavioral score was negatively correlated with SDNN ( $r=$ $-0.644, p=0.010)$, while escape duration was negatively correlated with both SDNN $(r=-0.699, p$ $=0.004)$ and $\operatorname{RMSSD}(r=-0.614, p=0.015)$.

For the most part, behavioral score was positively correlated with MHR in both sexes (Table 6), but not correlated with any other HR or HRV parameters. Escape duration was not significantly correlated with HR variables, but was negatively correlated with both SDNN $(r=-0.451, p=$ $0.035)$ and RMSSD in females $(r=-0.516, p=0.014)$.

\section{DISCUSSION}

A survey by Sackman and Houpt regarding horse personality which was assessed by horse owners, revealed that Thoroughbreds were the most nervous breed, whereas ponies had a less nervous 
personality [20]. Warmbloods had an intermediate level of nervousness. Other previous studies concur with this. A study exploring horse temperament reported that Thoroughbreds were ranked highly in breeds showing high excitability and anxiousness [21]. Another study demonstrated that ponies had lower anxiety scores than sport horses [22]. The results of the current study concur with these studies in that Thoroughbreds had significantly higher behavioral scores than other horse breeds. Jeju crossbred horseshad the lowest behavioral score in our study.

The neophobic response in horses is largely genetic [23]. A previous study exploring horse temperament has revealed the close association in temperament between Thoroughbreds and Arabians, which was inferred because of the origins of Thoroughbreds in Arabians, Barbs, and Turkomen breeding stock [20]. Jeju crossbred horses originated from crosses between Thoroughbred and Jeju horses. Thoroughbreds are renowned as being of nervous disposition [20], but Jeju horses are demonstrated to have a moderate and bolder temperament [12]. Therefore, the Jeju crossbreds may have attenuated the vigilant traits in Thoroughbreds, which was identified in the present study. Kim et al. revealed that the gentleness, patience, and aggressiveness, patience, and aggressiveness had moderate heritabilities, and that sensitivity had a high heritability in the temperament of Jeju crossbred horses [10]. So, selected breeding for appropriate temperament would be effective for optimal utility in this breed.

Significantly higher BHR in Jeju crossbreds compared to Warmbloods was attributed to their different body size. It was identified that body size and metabolic rate have significant relationship, so resting HR is faster in small equine breeds compared to larger ones [24]. In the current study, the results of cardiac activity after exposed to the novelty suggested that Thoroughbreds were more sensitive than Jeju crossbreds. There was no meaningful difference among breeds in MHR and Time to MHR, but RMSSD of HRV differed between Jeju crossbreds and Thoroughbreds. Individuals exposed to stressful situations have a lower vagal tone which means a regulatory shift toward sympathetic dominance, as seen in the lower RMSSD of Thoroughbreds compared with Jeju crossbreds, indicating increased vulnerability to stress. A change in HR may result from a combination of simultaneous transitions in activity, within both the vagal and sympathetic branches, so it has a limit in being used for accurately assessing sympathovagal balance as an index of psychological stress. On the other hand, HRV provides more accurate information on autonomic nervous system (ANS) regulation traits, and that is the reason why HRV is often coupled with HR parameters to obtain a clearer measure of stress in many animals [5]. Because changes in the sympathetic nervous system indicate the arousal dimension of the effect [25], our findings seem to suggest that Jeju crossbreds are less astonished by the novel object compared with the others.

It was stressed out the importance of gonadotropin action for the maturation of male, and the increase in sex related genes expression with increasing age [26]. A previous study revealed significant temperament differences between stallions and mares, as well as between stallions and geldings, but not between mares and geldings [27]. This outcome is likely because geldings are castrated and produce considerably less testosterone than stallions. The resultant effects on secondary sex traits could explain the lack of clear temperament differences between mares and geldings. Our result concurs with this hypothesis. The current study did not reveal any obvious sex differences in behavioral parameters.

Differences in HR and HRV responses between females and geldings were also not detected. A previous evaluation of temperament using behavioral and cardiac responses did not find clear sex differences between mares and geldings [28]. Another study examining sex differences in novelobject response among young horses (9-22 months old) revealed that sex did not influence HR variation [8]. Our results in this study are in line with the previous findings, given that geldings have similar testosterone production as juvenile male horses. 
The effect of age on temperament is debatable. A previous study reported that older horses had a significantly higher behavioral reactivity to novel stimuli than younger horses [27]. In contrast, another study on horses < 22 months old found that behavioral response frequency to a novel object decreased with increasing age [29]. Yet other study suggested that age had no influence on horse temperament [30], as did the current study, because no correlations between age and behavioral parameters was identified in this study. With regard to cardiac variables, age was not significantly correlated with HR parameters in this study, but was negatively correlated with some HRV variables. A low SDNN and RMSSD typically signals sympathetic activation associated with stressful circumstances. Previous research showed that older horses were less behaviorally responsive to stressful stimuli than younger horses, but exhibited a shift toward control by the sympathetic nervous system, which was indicated by a lower standard deviation of the beat-to-beat intervals (SDRR, in ms) and RMSSD [31]. SDRR is regarded as the same as SDNN, and representation of the data is identical [32]. These partially matched with the results of this study. In this study, even though behavioral responses and age had positive correlation coefficients, the correlations were not significant. However, it was revealed that older horses showed significantly decreased SDNN and RMSSD values than younger horses, implying a higher degree of stress.

This phenomenon might be due to training obscuring the natural responses of horses to unexpected stimuli, as demonstrated by a previous study [33]. Mature 'schooled' horses trained to stay in place do not always exhibit typical behavioral responses, whereas younger horses with less training tend to run away when surprised. This influence of training suggests that behavioral and HR reactivity to the novel object test may not be fully reflective of temperament. However, with additional HRV data, we might better predict stress levels, increasing the accuracy of temperament assessments. Therefore, even if the older horses in this study did not reveal or show lower behavioral or HR responses due to training when compared to younger horses, they were able to be more nervous to the unfamiliar objects than young horses.

Many studies on horses have demonstrated significant correlations between behavioral and cardiac variables during novel object tests $[6,34,35]$, which concluded that both of these methods should be used to draw comprehensive assessment of stress reactions. Our study corroborated previous researches showing that behavioral score was highly correlated with MHR in all horse groups. Increased HR is accepted as a proxy for fear in novel object tests in horses $[5,8]$, therefore, the current study suggests that the stronger the behavioral score, the more fear the horses felt normally.

In each breed and sex group, the correlation results between behavioral and cardiac parameters highlighted the characteristics of each group. A previous study with Hanoverian horses identified there were strong correlations between both reactivity and the time to calm down, and both HR and RMSSD, after a horse was exposed to a suddenly moving stimulus [28]. In the present study, Thoroughbreds and females exhibited the highest correlations between behavioral and cardiac parameters compared with other breed or sex groups. Lower HRV indices (SDNN and RMSSD) indicates a shift in physiological control to the sympathetic nervous system after a lack of sufficient parasympathetic counteraction [5]. Horses with a low parasympathetic response are more stressed $[8,36]$. It was reported that evaluations of emotional state in horses with a behavior reaction are easier to perform in Thoroughbreds than other breeds, and the frequency of escape attempts is the most appropriate behavioral reactivity for the assessment of the emotional state of that breed [37]. Our results show that there are significant correlations between behavioral reactions and emotional state, especially in Thoroughbreds and females. These two groups specifically showed high correlation frequency between escape duration and both SDNN and RMSSD compared to other breed and sex groups. The results suggest that escape duration might be useful to detect 
stress levels, especially in certain horse groups for which behavioral differences are not detected. Thus, the potential value of escape duration indices in predicting the stress levels of animals, and complementing other HR and HRV parameters with more horse breeds need to be further explored.

Like many traits, temperament has both environmental and genetic components. According to the previous study [38], the effect of habituation is applied to very specific object, so horses could show surprising responses to the novel thing even after habituation to the similar object. For example, the fear reaction to the tarp remained after one week despite the habituation to the umbrella. In this study, environmental factors were minimized as much as possible through testing horses that were born on a single farm, or had resided there for at least 1 year by the time of the experiment. However, differences in recent living background and previous experience which was unknown to researcher among some of subjects before the experiment could lead to environmental effects overshadowing hereditary effects in the temperament test. Therefore, studies focusing on environmental factors are necessary for a better understanding of horse temperament in the future.

\section{CONCLUSION}

In conclusion, our study identified clear differences between breeds in behavioral and cardiac parameters when responding to a novel stimulus. The temperament of Jeju crossbreds, derived from a Korean native pony, is rarely studied, despite their popular usage in Korea for horseback riding. In particular, Thoroughbreds exhibited greater responses, and hence more stress than Jeju crossbreds. Sex differences in temperament were not detected. However, age was negatively correlated with SDNN and RMSSD, possibly due to increased experience with training among older horses. Thoroughbred and female groups had stronger correlations between escape duration and certain HRV indices, implying that escape duration might be used as stress indicator. The findings of this study will improve the prediction of sensitivity of responses of horses to novel objects based on breed, sex, or age. Horses can be matched on the basis of level of experience of the rider (less nervous horses more suitable for beginners) with the results, thus lowering the risk of horseback riding. These findings will contribute to efforts aimed at improving horse welfare and safety, while also providing means to increase the potential economic benefits.

\section{REFERENCES}

1. Shapira I, Sultan H, Shanas U. Agricultural farming alters predator-prey interactions in nearby natural habitats. Anim Conserv. 2008;11:1-8. https://doi.org/10.1111/j.1469-1795.2007.00145.x

2. Monika B, Jarosław K, Beata M, Leszek S. Relationships between thoroughbreds' contribution in the pedigree and the level of fearfulness and performance in warmblood stallions. Acta Vet. 2018;68:288-300. https://doi.org/10.2478/acve-2018-0025

3. Leiner L, Fendt M. Behavioural fear and heart rate responses of horses after exposure to novel objectseffects of habituation. Appl Anim Behav Sci. 2011;131:104-9. https://doi.org/10.1016/ j.applanim.2011.02.004

4. Graf P, von Borstel UK, Gauly M. Importance of personality traits in horses to breeders and riders.J Vet Behav. 2013;8:316-25. https://doi.org/10.1016/j.jveb.2013.05.006

5. Von Borell E, Langbein J, Després G, Hansen S, Leterrier C, Marchant-Forde J, et al. Heart rate variability as a measure of autonomic regulation of cardiac activity for assessing stress and welfare in farm animals—a review. Physiol Behav. 2007;92:293-316. https://doi.org/10.1016/ j.physbeh.2007.01.007 
6. Christensen JW, Keeling LJ, Nielsen BL. Responses of horses to novel visual, olfactory and auditory stimuli. Appl Anim Behav Sci. 2005;93:53-65. https://doi.org/10.1016/j.applanim.2005.06.017

7. Lansade L, Bouissou MF, Erhard HW. Fearfulness in horses: a temperament trait stable across time and situations. Appl Anim Behav Sci. 2008;115:182-200. https://doi.org/10.1016/j.applanim.2008.06.011

8. Visser EK, Van Reenen CG, Van der Werf JTN, Schilder MBH, Knaap JH, Barneveld A, et al. Heart rate and heart rate variability during a novel object test and a handling test in young horses. Physiol Behav. 2002;76:289-96. https://doi.org/10.1016/S0031-9384(02)00698-4

9. Kim NY, Seong HS, Kim DC, Park NG, Yang BC, Son JK, et al. Genome-wide analyses of the Jeju, Thoroughbred, and Jeju crossbred horse populations using the high density SNP array. Genes Genomics. 2018;40:1249-58. https://doi.org/10.1007/s13258-018-0722-0

10. Kim NY, Son JK, Cho IC, Shin SM, Park SH, Seong PN, et al. Estimation of genetic parameters for temperament in Jeju crossbred horses. Asian-Australas J Anim Sci. 2018;31:1098-102. https://doi.org/10.5713/ajas.17.0252

11. Choi SC, Yang JH, Ryu EA. A study on the diversification strategy of under-utilized horses. Gyeonggi: Korea Racing Authority (KRA); 2019.

12. Yoon MJ, Kim BS, Do KT, Jung HJ, Kim JY, Choi YJ, et al. Research for developing a Korean riding horse breed (Halla horse). Gyeonggi: Korea Racing Authority (KRA); 2019.

13. Hintze S, Murphy E, Bachmann I, Wemelsfelder F, Würbel H. Qualitative behaviour assessment of horses exposed to short-term emotional treatments. Appl Anim Behav Sci. 2017;196:44-51. https://doi.org/10.1016/j.applanim.2017.06.012

14. Kim BS, Kim JG, Chung SH. Assessment of heart rate and behavioral response for the prediction of effectiveness of desensitization training in horses. Ann Anim Resour Sci. 2018;29:3341. https://doi.org/10.12718/AARS.2018.29.1.33

15. Søndergaard E, Jago J. The effect of early handling of foals on their reaction to handling, humans and novelty, and the foal-mare relationship. Appl Anim Behav Sci. 2010;123:93-100. https://doi.org/10.1016/j.applanim.2010.01.006

16. Brunberg E, Gille S, Mikko S, Lindgren G, Keeling LJ. Icelandic horses with the silver coat colour show altered behaviour in a fear reaction test. Appl Anim Behav Sci. 2013;146:72-8. https://doi.org/10.1016/j.applanim.2013.04.005

17. Christensen JW, Malmkvist J, Nielsen BL, Keeling LJ. Effects of a calm companion on fear reactions in naive test horses. Equine Vet J. 2008;40:46-50. https://doi. org/10.2746/042516408X245171

18. Castaldo R, Montesinos L, Melillo P, James C, Pecchia L. Ultra-short term HRV features as surrogates of short term HRV: a case study on mental stress detection in real life. BMC Med Inform Decis Mak. 2019;19:1-13. https://doi.org/10.1186/s12911-019-0742-y

19. Ille N, Erber R, Aurich C, Aurich J. Comparison of heart rate and heart rate variability obtained by heart rate monitors and simultaneously recorded electrocardiogram signals in nonexercising horses.J Vet Behav. 2014;9:341-6. https://doi.org/10.1016/j.jveb.2014.07.006

20. Sackman JE, Houpt KA. Equine personality: association with breed, use, and husbandry factors.J Equine Vet Sci. 2019;72:47-55. https://doi.org/10.1016/j.jevs.2018.10.018

21. Lloyd AS, Martin JE, Bornett-Gauci HLI, Wilkinson RG. Horse personality: variation between breeds. Appl Anim Behav Sci. 2008;112:369-83. https://doi.org/10.1016/j.applanim.2007.08.010

22. Roberts K, Hemmings AJ, Moore-Colyer M, Parker MO, McBride SD. Neural modulators of temperament: a multivariate approach to personality trait identification in the horse. Physiol 
Behav. 2016;167:125-31.https://doi.org/10.1016/j.physbeh.2016.08.029

23. Hausberger M, Bruderer C, Le Scolan N, Pierre JS. Interplay between environmental and genetic factors in temperament / personality traits in horses (Equus caballus). J Comp Psychol. 2004;118:434-46. https://doi.org/10.1037/0735-7036.118.4.434

24. Schwarzwald CC, Kedo M, Birkmann K, Hamlin RL. Relationship of heart rate and electrocardiographic time intervals to body mass in horses and ponies. J Vet Cardiol. 2012;14:343-50. https://doi.org/10.1016/j.jvc.2012.03.001

25. Yeates JW, Main DCJ. Assessment of positive welfare: a review. Vet J. 2008;175:293-300. https://doi.org/10.1016/j.tvj1.2007.05.009

26. Herrera-Luna CV, Scarlet D, Walter I, Aurich C. Effect of stallion age on the expression of LH and FSH receptors and aromatase P450 in equine male reproductive tissues. 2016;28:2016-26. https://doi.org/10.1071/RD15027

27. Graf P, Von Borstel UK, Gauly M. Practical considerations regarding the implementation of a temperament test into horse performance tests: results of a large-scale test run.J Vet Behav. 2014;9:329-40. https://doi.org/10.1016/j.jveb.2014.08.004

28. Von Borstel UK, Euent S, Graf P, König S, Gauly M. Equine behaviour and heart rate in temperament tests with or without rider or handler. Physiol Behav. 2011;104:454-63. https://doi. org/10.1016/j.physbeh.2011.05.010

29. Visser EK, van Reenen CG, Hopster H, Schilder MBH, Knaap JH, Barneveld A, et al. Quantifying aspects of young horses' temperament: consistency of behavioural variables. Appl Anim Behav Sci. 2001;74:241-58. https://doi.org/10.1016/S0168-1591(01)00177-0

30. Wolff A, Hausberger M, Le Scolan N. Experimental tests to assess emotionality in horses. Behav Proc. 1997;40:209-21. https://doi.org/10.1016/S0376-6357(97)00784-5

31. Baragli P, Vitale V, Banti L, Sighieri C. Effect of aging on behavioural and physiological responses to a stressful stimulus in horses (Equus caballus). Behaviour. 2014;151:1513-33. https://doi.org/10.1163/1568539X-00003197

32. Shaffer F, Ginsberg JP. An overview of heart rate variability metrics and norms. Front Public Health. 2017;5:1-17.https://doi.org/10.3389/fpubh.2017.00258

33. Munsters CCBM, Visser KEK, van den Broek J, van Oldruitenborgh-Oosterbaan MMS. The influence of challenging objects and horse-rider matching on heart rate, heart rate variability and behavioural score in riding horses. Vet J. 2012;192:75-80. https://doi.org/10.1016/j.tvj1.2011.04.011

34. Wilk I, Janczarek I, Zastrzeżyńska M. Assessing the suitability of Thoroughbred horses for equestrian sports after their racing careers. J Vat Behav. 2016;15:43-9. https://doi.org/10.1016/ j.jveb.2016.08.075

35. Young T, Creighton E, Smith T, Hosie C. A novel scale of behavioural indicators of stress for use with domestic horses. Appl Anim Behav Sci. 2012;140:33-43. https://doi.org/10.1016/ j.applanim.2012.05.008

36. Janczarek I, Stachurska A, Wilk I, Krakowski L, Przetacznik M, Zastrzeżyńska M, et al. Emotional excitability and behaviour of horses in response to stroking various regions of the body. Anim Sci J. 2018;89:1599-608. https://doi.org/10.1111/asj.13104

37. Wilk I, Janczarek I. Relationship between behavior and cardiac response to round pen training. J Vet Behav. 2015;10:231-6. https://doi.org/10.1016/j.jveb.2015.01.001

38. Christensen JW, Zharkikh T, Ladewig J. Do horses generalise between objects during habituation? Appl Anim Behav Sci. 2008;114:509-20. https://doi.org/10.1016/j.applanim.2008.03.007 